Supporting Information

\title{
Wettability reversal on dolomite surfaces by divalent ions and surfactants: An experimental and molecular dynamics simulation study
}

\author{
Shixun Bai ${ }^{\mathrm{a}}$, Jan Kubelka ${ }^{\mathrm{a}, *}$, and Mohammad Piri ${ }^{\mathrm{a}}$ \\ ${ }^{a}$ Center of Innovation for Flow through Porous Media, Department of Petroleum Engineering, University \\ of Wyoming, Laramie, Wyoming 82071, United States \\ *Corresponding author. Tel: 1- (307)761-4056 \\ Email address: sbai@uwyo.edu (Shixun Bai), ikubelka@uwyo.edu (Jan Kubelka), mpiri@uwyo.edu \\ (Mohammad Piri)
}

\section{Table of Contents}

Table S1. Experiments, material, and comparison between sequence of fluid introduction

Table S2. Force fields used for molecules and ions in this study

Figure S1. Demonstration of the acute and obtuse steps, and the vacancies along the $\{\overline{4} 41\}$ direction

Figure S2. Demonstration of the acute and obtuse steps, and the vacancies along the $\{48 \overline{1}\}$ direction

Figure S3. Distance between four individual $\mathrm{Cl}^{-}$ions and the surface for Type I and II point defects

Figure S4. Interaction potentials between different groups of molecules for oil detachment

Figure S5. Snapshots of the carboxylate detachment process at the acute $\{\overline{4} 41\}$ step vacancy

Figure S6. Snapshots of the carboxylate detachment process at the obtuse $\{\overline{4} 41\}$ step vacancy

Figure S7. Snapshots of the carboxylate detachment process at the obtuse $\{48 \overline{1}\}$ step vacancy

Figure S8. Diagram of the wettability reversal mechanism by PDI

Figure S9. Snapshot of carboxylate adsorption at the acute $\{\overline{4} 41\}$ step vacancy in the presence of $\mathrm{CaCl}_{2}$ 
Table S1 Experiments, material, and comparison between sequence of fluid introduction

\begin{tabular}{|l|l|l|}
\hline \multicolumn{1}{|c|}{ Experiments } & \multicolumn{1}{|c|}{ Material } & Sequence of fluid introduction \\
\hline $\begin{array}{l}\text { Wettability reversal } \\
\text { by surfactants }\end{array}$ & $\begin{array}{l}\text { Distilled water, cationic and anionic } \\
\text { surfactant solutions }\end{array}$ & $\begin{array}{l}\text { Oil was introduced onto the chips first, } \\
\text { followed by the water phase }\end{array}$ \\
\hline $\begin{array}{l}\text { Wettability reversal } \\
\text { by PDIs }\end{array}$ & $\begin{array}{l}\mathrm{CaCl}, \mathrm{MgCl}_{2}, \mathrm{Na}_{2} \mathrm{SO}_{4}, \text { and } \mathrm{MgSO}_{4} \\
\text { solutions }\end{array}$ & $\begin{array}{l}\text { Brine was introduced onto the chips } \\
\text { first, the chips were then dried before } \\
\text { the introduction of oil on the chip } \\
\text { surface }\end{array}$ \\
\hline
\end{tabular}

Table S2 Force fields used for molecules and ions in this study

\begin{tabular}{|c|c|c|}
\hline Atom/molecule & MD representation & Force field used \\
\hline $\mathrm{Ca}^{2+}$ & & \multirow{6}{*}{ Demichelils et al. ${ }^{44}$} \\
\hline $\mathrm{Mg}^{2+}$ & & \\
\hline $\mathrm{Na}^{+}$ & & \\
\hline $\mathrm{CO}_{3}{ }^{2-}$ & & \\
\hline $\mathrm{HCO}_{3}^{-}$ & & \\
\hline \multicolumn{2}{|l|}{$\mathrm{H}_{2} \mathrm{O}$} & \\
\hline $\mathrm{SO}_{4}{ }^{2-}$ & & $\begin{array}{c}\text { Zeron et al. }{ }^{45} \\
\text { (including interactions between } \\
\mathrm{SO}_{4}{ }^{2-}, \mathrm{Na}^{+} \text {, and } \mathrm{Mg}^{2+} \text { ) }\end{array}$ \\
\hline $\mathrm{Cl}^{-}$ & & \multirow{2}{*}{ CHARMM $36^{46}$} \\
\hline Heptane & & \\
\hline Octanoate & & \multirow{3}{*}{$\begin{array}{c}\text { CHARMM } 36^{46} \text { with partial } \\
\text { charges assigned using QM DFT } \\
\text { calculations }\end{array}$} \\
\hline Cationic surfactant & & \\
\hline Anionic surfactant & & \\
\hline
\end{tabular}




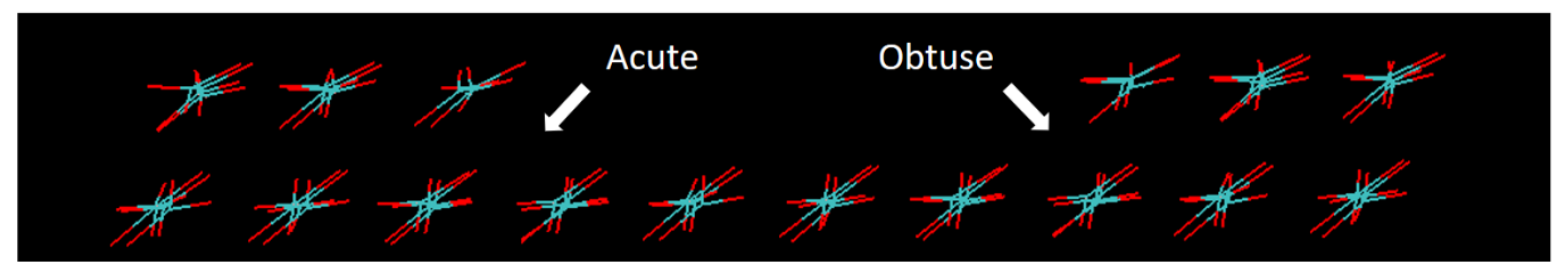

(a)

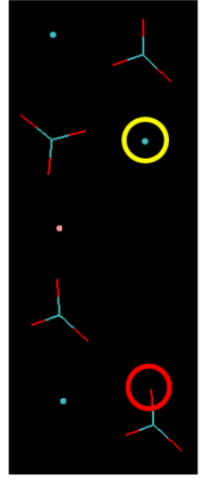

(b)

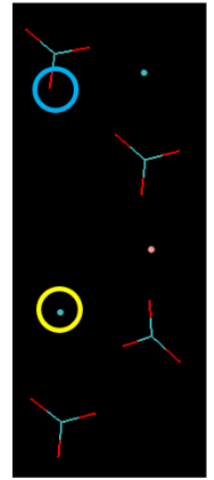

(c)

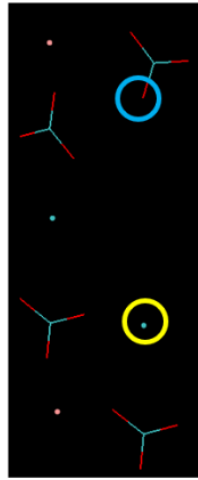

(d)

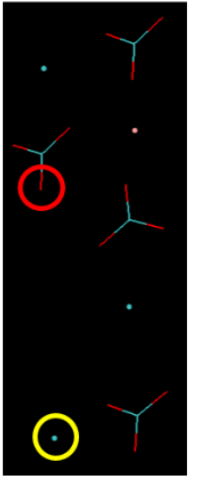

(e)

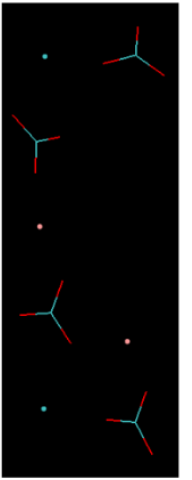

(f)

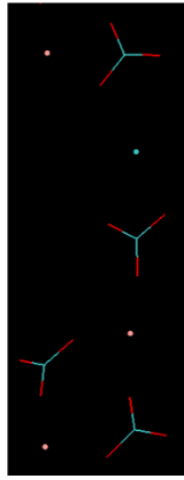

(g)

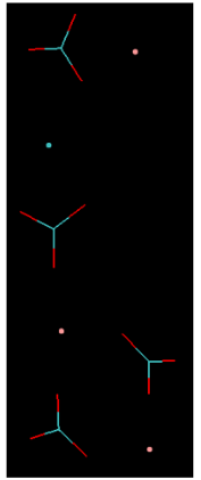

(h)

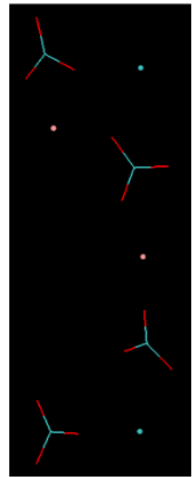

(i)

Figure S1. (a) Demonstration of the acute and obtuse steps along the $\{\overline{4} 41\}$ direction. (b)(d)(f)(h) Top views of the four possible configurations of vacancies created on the acute steps along the $\{\overline{4} 41\}$ direction; (c)(e)(g)(i) Top views of the four possible configurations of vacancies created on the obtuse steps along the $\{\overline{\mathbf{4}} 41\}$ direction. The exposed $\mathrm{Ca}^{2+}$ ions are marked with yellow circles, and the oxygen atoms of the carbonate ions facing away from and into the surface are marked with red and blue circles, respectively. 


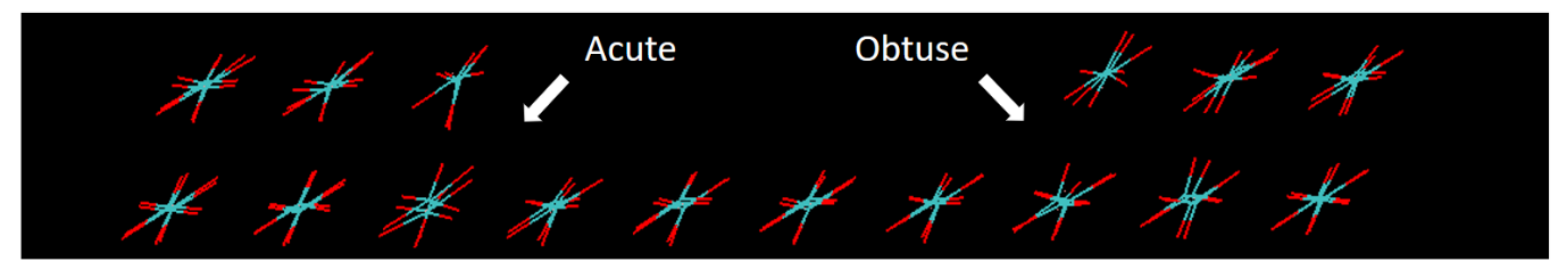

(a)

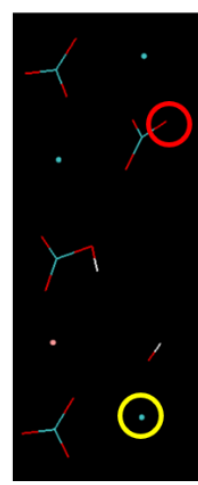

(b)

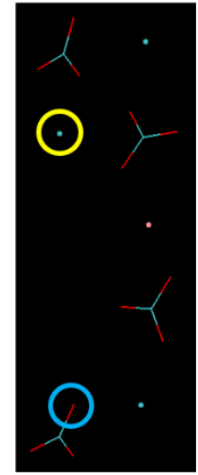

(c)

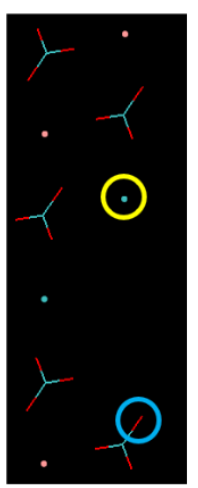

(d)

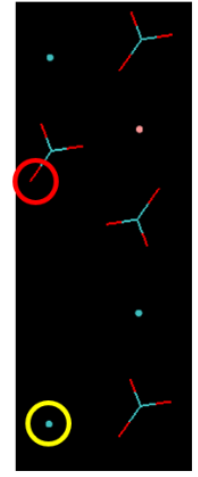

(e)

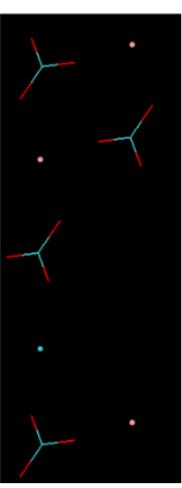

(f)

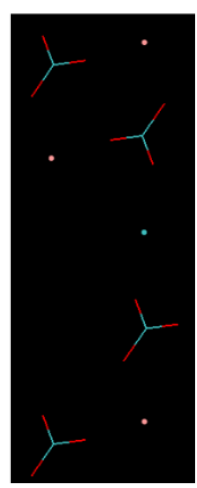

(g)

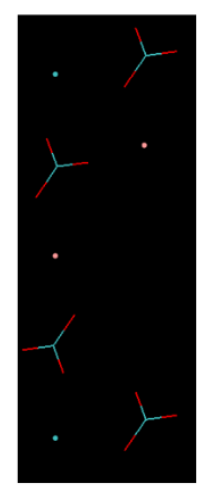

(h)

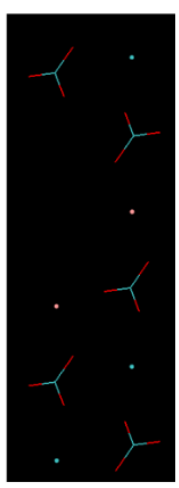

(i)

Figure S2. (a) Demonstration of the acute and obtuse steps along the $\{48 \overline{1}\}$ direction.(b)(d)(f)(h) Top views of the four possible configurations of vacancies created on the acute steps along the $\{48 \overline{1}\}$ direction; (c)(e)(g)(i) Top views of the four possible configurations of vacancies created on the obtuse steps along the $\{48 \overline{1}\}$ direction The exposed $\mathrm{Ca}^{2+}$ ions are marked with yellow circles, and the oxygen atoms of the carbonate ions facing away from and into the surface are marked with red and blue circles, respectively. 

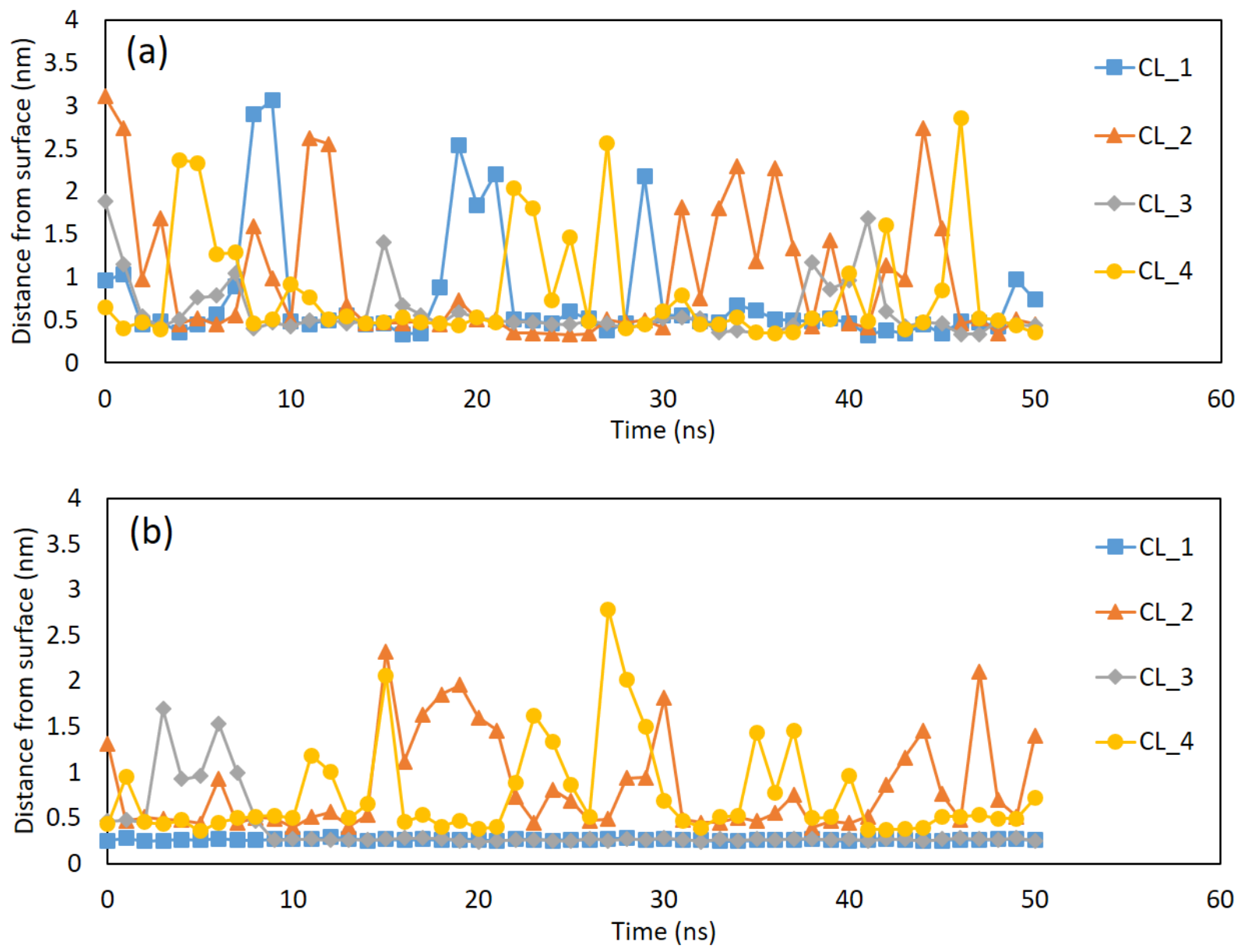

Figure S3. Distance between four individual $\mathrm{Cl}^{-}$ions (as shown in Figure 7) and the dolomite surface with (a) two Type I and (b) two Type II point defects over the $\mathbf{5 0}$ ns simulation. 


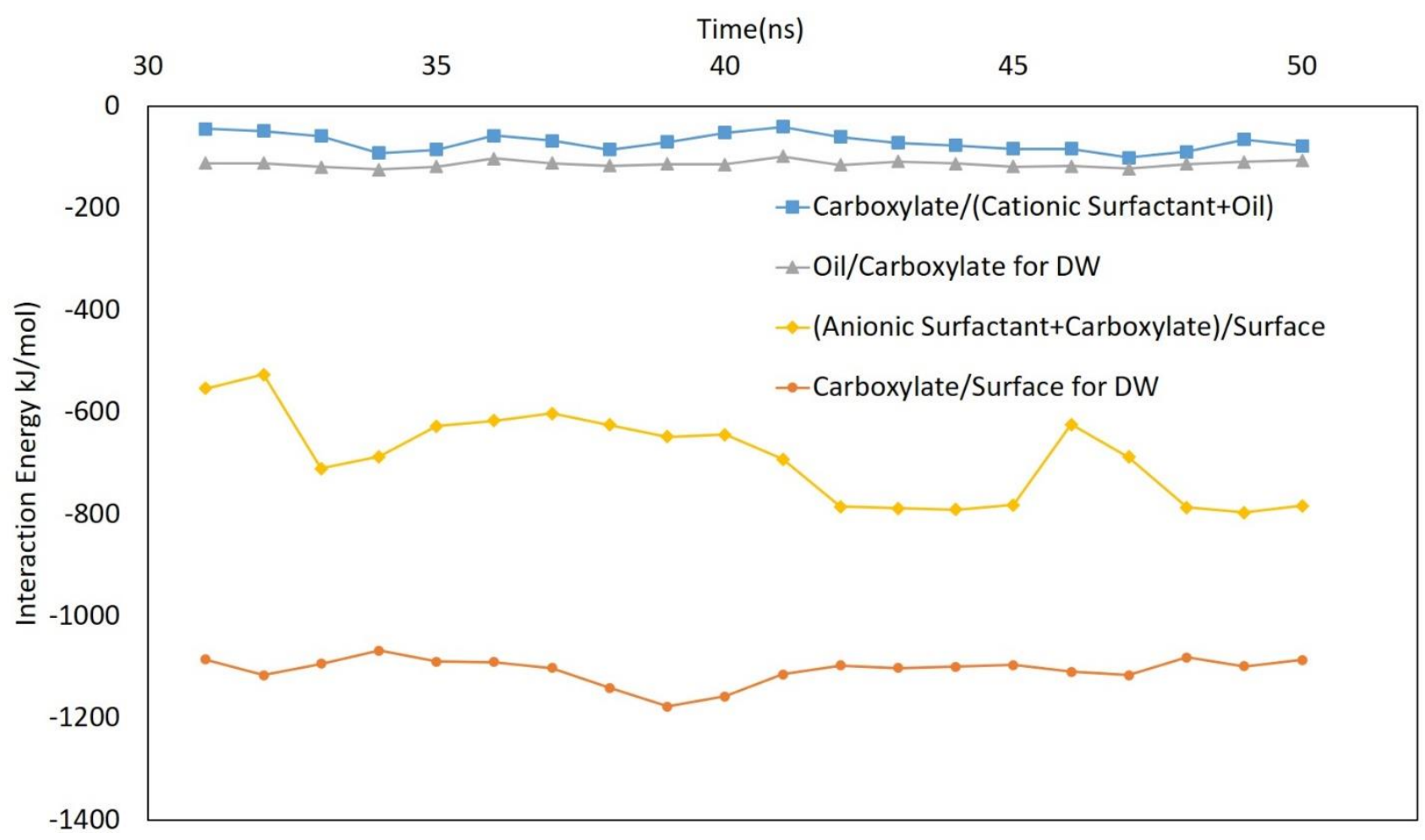

Figure S4. Interaction potentials between different groups of molecules during the last $\mathbf{2 0}$ ns of the $\mathbf{5 0}$ ns simulation, when the systems were relatively stabilized. 

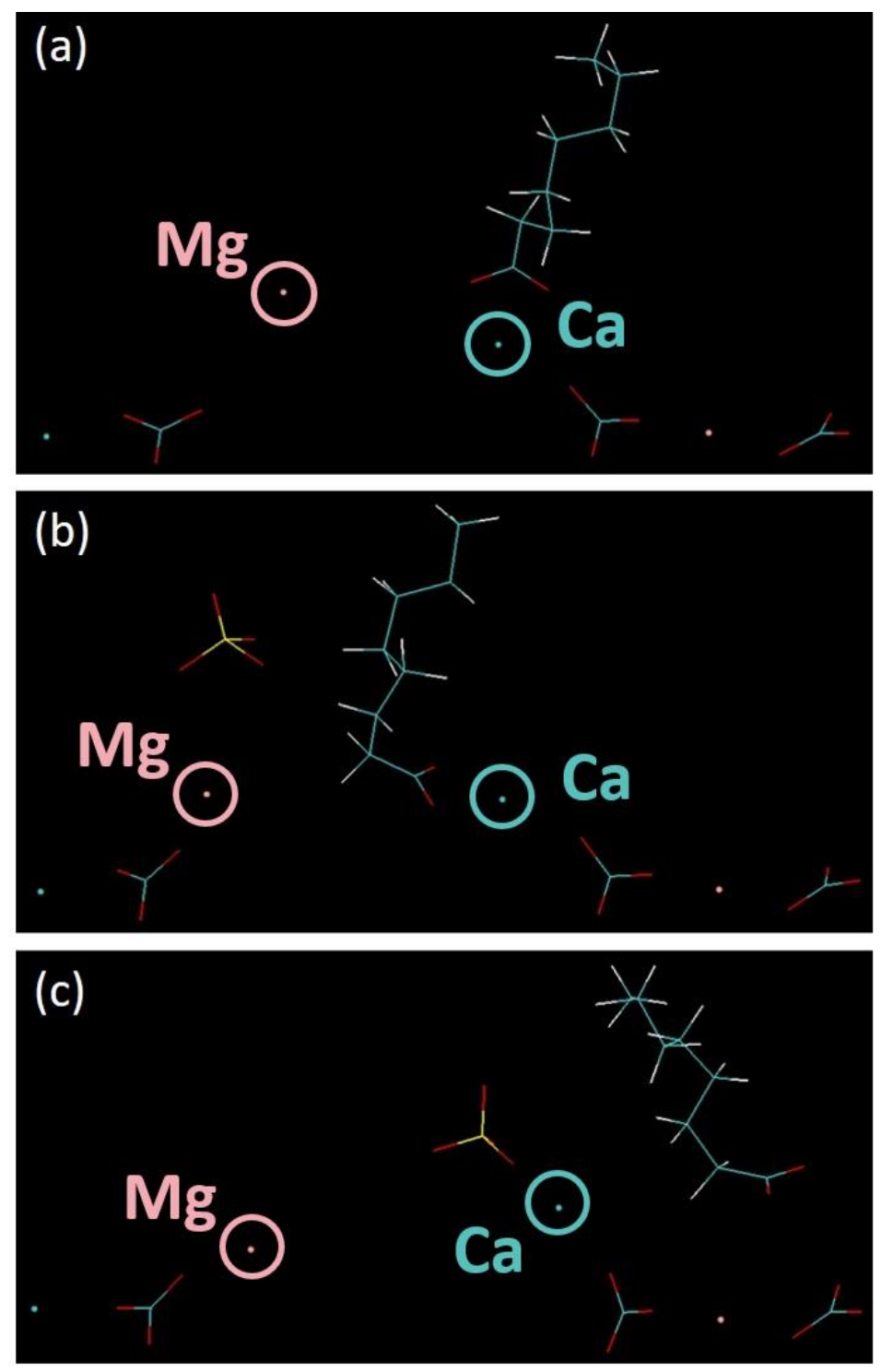

Figure S5. Snapshots of the carboxylate detachment process at the acute $\{\overline{4} 41\}$ step vacancy. (a) $\mathrm{A} \mathrm{Mg}^{2+}$ was adsorbed at the exposed carbonate ion; (b) a $\mathrm{SO}_{4}{ }^{2-}$ ion was drawn close to the surface via electrostatic attraction by the adsorbed $\mathrm{Mg}^{2+}$; (c) the $\mathrm{SO}_{4}{ }^{2-}$ was captured by the $\mathrm{Ca}^{2+}$ responsible for anchoring the carboxylate on the surface, and as a result the carboxylate was detached due to electrostatic repulsion from the $\mathrm{SO}_{4}{ }^{2-}$. Water molecules are not shown for clarity. The snapshots were taken at $0 \mathrm{~ns}, 2.5 \mathrm{~ns}$, and $3.2 \mathrm{~ns}$, respectively. 

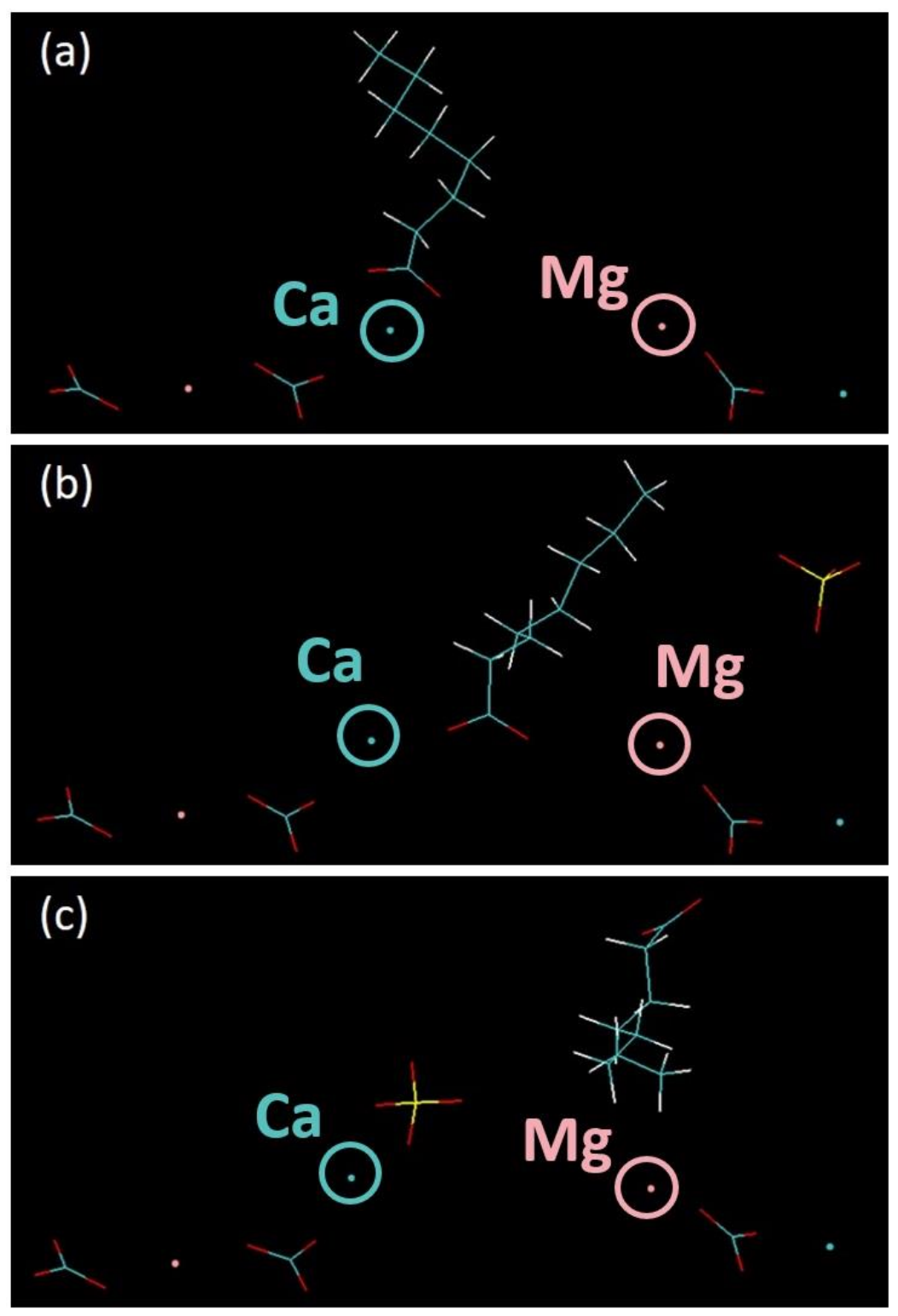

Figure S6. Snapshots of the carboxylate detachment process at the obtuse $\{\overline{4} 41\}$ step vacancy. (a) A $\mathrm{Mg}^{2+}$ was adsorbed at the exposed carbonate ion; (b) a $\mathrm{SO}_{4}{ }^{2-}$ ion was drawn close to the surface via electrostatic attraction by the adsorbed $\mathrm{Mg}^{2+}$; (c) the $\mathrm{SO}_{4}{ }^{2-}$ was captured by the $\mathrm{Ca}^{2+}$ responsible for anchoring the carboxylate on the surface, and as a result the carboxylate was detached due to electrostatic repulsion from the $\mathrm{SO}_{4}{ }^{2-}$. Water molecules are not shown for clarity. The snapshots were taken at $0 \mathrm{~ns}, 1.8 \mathrm{~ns}$, and $2.0 \mathrm{~ns}$, respectively. 

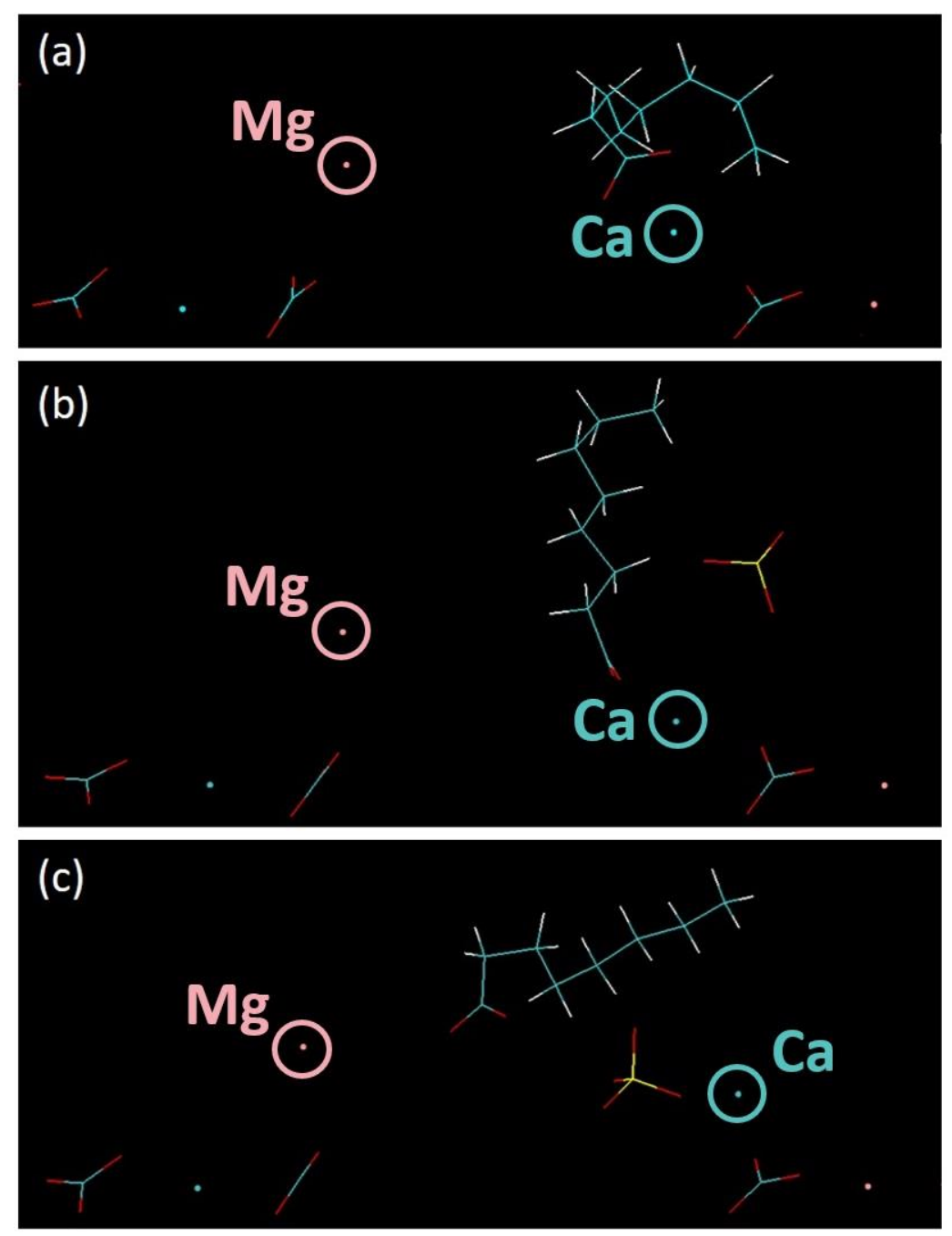

Figure S7. Snapshots of the carboxylate detachment process at the obtuse $\{48 \overline{1}\}$ step vacancy. (a) A $\mathrm{Mg}^{2+}$ was adsorbed at the exposed carbonate ion; (b) a $\mathrm{SO}_{4}{ }^{2-}$ ion was drawn close to the surface via electrostatic attraction by the adsorbed $\mathrm{Mg}^{2+}$; (c) the $\mathrm{SO}_{4}{ }^{2-}$ was captured by the $\mathrm{Ca}^{2+}$ responsible for anchoring the carboxylate on the surface, and as a result the carboxylate was detached due to electrostatic repulsion from the $\mathrm{SO}_{4}{ }^{2-}$. Water molecules are not shown for clarity. The snapshots were taken at $0 \mathrm{~ns}, 1.1 \mathrm{~ns}$, and $3.0 \mathrm{~ns}$, respectively. 
(a)

Surface

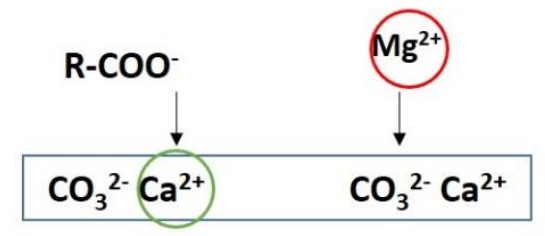

(b)

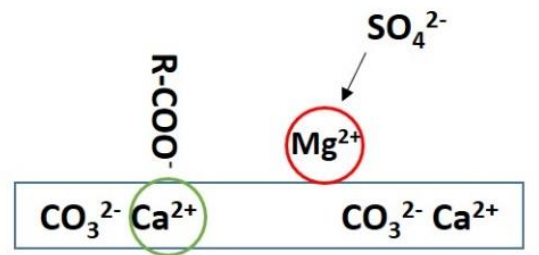

(c)

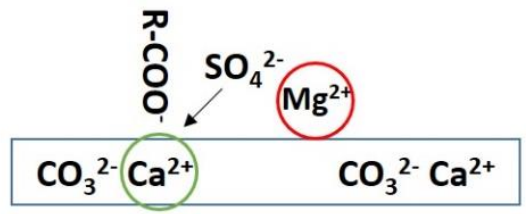

(d)

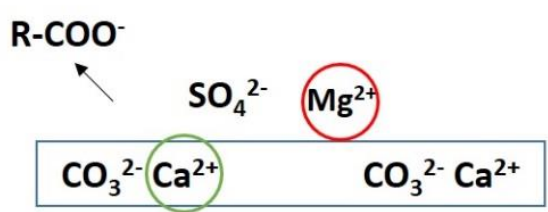

Figure S8. A diagram illustrating the wettability and its reversal processes on the dolomite step vacancies. (a) A carboxylate molecule is electrostatically adsorbed at the exposed surface $\mathrm{Ca}^{2+}$, resulting in the oil-wetness of the surface, while a $\mathrm{Mg}^{2+}$ ion is attracted to the vicinity of the surface by the exposed surface $\mathrm{CO}_{3}{ }^{2-} ;$ (b) a $\mathrm{SO}_{4}{ }^{2-}$ ion is electrostatically attracted near the surface by the pre-adsorbed $\mathrm{Mg}^{2+}$; (c) the interaction between the $\mathrm{SO}_{4}{ }^{2-}$ ion and the bridging $\mathrm{Ca}^{2+}$ gets strong enough at elevated temperatures; and (d) the $\mathrm{SO}_{4}{ }^{2-}$ ion displaces the carboxylate molecule from the bridging $\mathrm{Ca}^{2+}$ via competitive adsorption, thereby restoring the water-wetness of the surface.

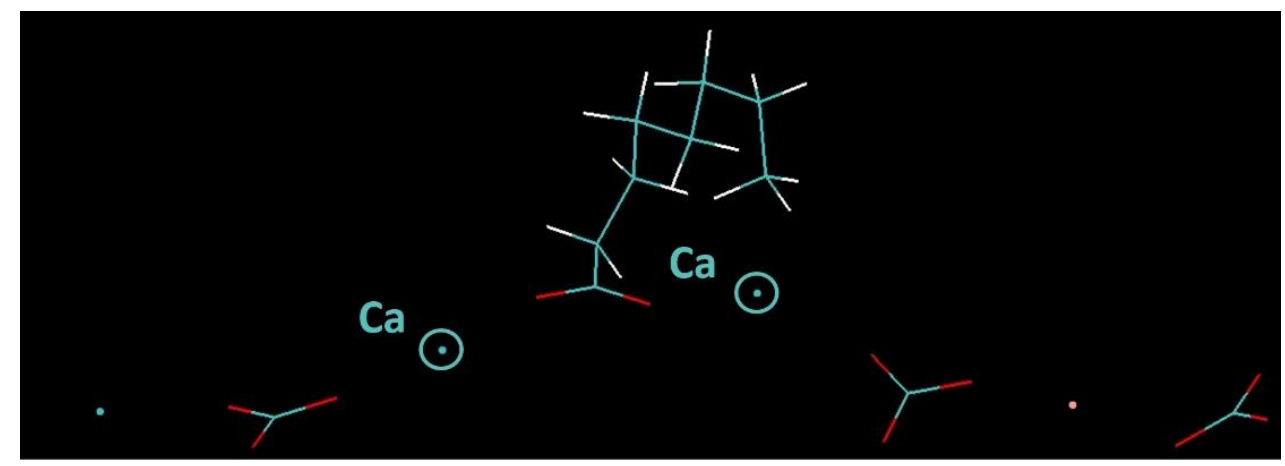

Figure S9. A snapshot of carboxylate adsorption at the acute $\{\overline{4} 41\}$ step vacancy with $\mathrm{CaCl}_{2}$ solution being the water phase. The octanoate molecule was kept on the dolomite surface by two $\mathrm{Ca}^{2+}$, one originally from the dolomite lattice and another from adsorption of an aqueous $\mathrm{Ca}^{2+}$ on the exposed surface $\mathrm{CO}_{3}{ }^{2-}$. Water molecules are not shown for clarity. 